\title{
Environment Friendly Voltage Up-gradation Model for Distribution Power Systems
}

\author{
K. Nithiyananthan ${ }^{1}$, Umasankar ${ }^{2}$ \\ ${ }^{1}$ Department of Electrical and Electronics Engineering, Karpagam College of Engineering, Coimbatore 641032, \\ Tamil Nadu, India \\ ${ }^{2}$ Birla Institute of Technology and Science (BITS) Pilani, Dubai Campus, Dubai, United Arab Emirates
}

\begin{tabular}{l} 
Article Info \\
\hline Article history: \\
Received Feb 6, 2016 \\
Revised Jul 3, 2016 \\
Accepted Jul 16, 2016 \\
\hline Keyword: \\
Current loss calculation \\
Distribution Power systems \\
Distribution transformer \\
Pocket substation \\
Ring main \\
Substation \\
Touch voltage \\
Transmission lines \\
Voltage up gradation
\end{tabular}

Article Info

Revised Jul 3, 2016

\begin{abstract}
The main aim of this research work is to analyze and develop voltage up gradation procedure model for effective \& economic power distribution in urban and suburban area. Voltage up gradation from $6.6 \mathrm{KV}$ to $11 \mathrm{KV}$ of the distribution power system network has been considered for the proposed research work. Electric power consumption has been increasing uninterruptedly, being this increase specially accelerated in the last few years. Nowadays electric lines are saturated; they are reaching critical values of ampere capacity and sag. Therefore, building new lines has been necessary to provide the ever increasing consumption. The difficulty to find new corridors to construct new distribution lines, underground cables is increasing in cities, industrial areas and in many cases it is simply impossible. The construction of new electric lines is increasing difficulty, thus there is a need to look at alternatives that increases the power transfer capacity. Voltage up gradation of the existing electric cables/lines of the distribution system is the most viable solution and it stresses on the savings of power due to a reduction in system losses when the voltage is high. The proposed research work is to develop and analyze voltage up gradation procedures and protocols for converting $6.6 \mathrm{KV}$ network into $11 \mathrm{KV}$ network in a distributed system. It also takes into account the expenses incurred in the process and the various other important constraints.
\end{abstract}

Copyright (C) 2016 Institute of Advanced Engineering and Science. All rights reserved.

\section{Corresponding Author:}

K. Nithiyananthan,

Department of Electrical and Electronics Engineering,

Karpagam College of Engineering,

Coimbatore-641 032, Tamil Nadu India.

E-mail: nithiieee@yahoo.co.in

\section{INTRODUCTION}

Nowadays power systems are complex networks. The high density load poses great challenges for providing adequate transmission and distribution facilities. There are a large number of generating stations and load centers that are interconnected through power transmission lines. Electricity is generated and supplied to consumers via transmission and distribution networks. Power systems of the modern era are more reliable and serve customer load without any interruption in utility voltage. Generation facilities should have the capacity to produce the required power to meet the customer demand. It is the responsibility of the distribution system to deliver electricity to each customer's service entrance. Due to the greenhouse effect, the climate itself is changing, thereby putting the life of plants and animals at risk. Now the whole world is thinking about reducing the carbon emission for saving the earth. Different means for reducing the emission of greenhouse gases are thought of by different agreement made in this direction like Kyoto protocol where each nation has to reduce emission to an extend. In this case the one of the important areas is emitted from power generation. With increasing use of computers and voltage sensitive equipment, more and more 
customers are demanding higher reliability and quality of supply.Nowadays it is a competitive world, electricity generation and distribution is no exception to it. Hence, to reduce the cost of distribution and indirectly the cost of power generation by reducing the losses through an up gradation of voltage, to meet the highest load density requirements, the proposed work is taken up. The Australian distribution company involves a study analysis of up gradation of voltage from $66 / 6.6 \mathrm{KV}$ to $66 / 11 \mathrm{KV}$ in a network. After evaluating several alternative options, Western Power has concluded that the only feasible solution that will provide the required capacity [16] is to upgradation of operating voltage. Distribution network planning is primarily identified by the allocation and sizing of distribution transformers. The location of transformers directly specifies the length and route of MV and LV feeders. The practical aspects of the voltage upgradation procedure model have to be determined along with cost and time analysis. For this purpose, the voltage upgradation procedure model is required to minimize the investment cost of transformers and feeders, while, the loss cost is minimized and the system reliability is maximized. The voltage drop and the feeder current as constraints need to be maintained within their standard range. Although the LV network cost is, to some extent, comparable with the MV network cost, the majority of the published papers in planning of distribution networks are dedicated to the planning of MV networks [1-13].

\section{VOLTAGE UPGRADTION MODEL IMPLEMENTATION FOR PRIMARY/SECONDARY SUBSTATION}

Replacement of plant at the existing substation to convert the secondary side of the substation from $6.6 \mathrm{KV}$ to $11 \mathrm{KV}$ operation together with installing transformers of higher capacity. To convert the existing substation will present significant challenges. The work will involve the construction of a $66 / 11 \mathrm{KV}$ zone substation that is to be located on land immediately adjacent to the existing 66.6/6.6 KV substation. The new substation will be of a 66/11 KV design with two 33 MVA transformers and two incoming lines initially, with provision for a third transformer and a third line at some later date.

\section{SELECTION OF TRANSMISSION NETWORK}

Selection of the network is based on the voltage of the circuit, load on the circuit, depending upon the type of customer. Figure 1 shows the single line diagram of $33 \mathrm{KV}$ substation with incoming feeders IC, distribution transformer DT and outgoing feeders.

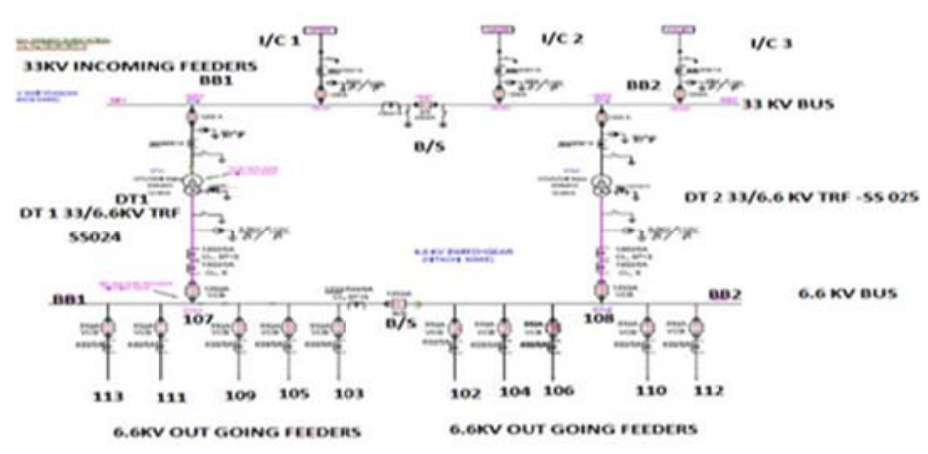

Figure 1. Typical Arrangement of Single Line Diagram of 33/6.6 KV Substation

Normally $33 \mathrm{KV}$ substation consists of two incoming feeders, bus section Bi/S and two transformer feeders. Figure 1 consists of three incoming feeders connected to $33 \mathrm{KV}$ bus. $4.33 \mathrm{KV}$ Bus bar (BB1 \& BB2) consists three incoming feeders $(\mathrm{I} / \mathrm{C} 1, \mathrm{I} / \mathrm{C} 2, \mathrm{I} / \mathrm{C} 3)$, bus section $(\mathrm{B} / \mathrm{S})$ and two transformer feeders. And also consists of two numbers10/15 MVA Distribution Transformers (DT 1 \& DT2) connected to Bus Bar1 \& 2, 13 nos $12 \mathrm{KV}$ switch gears which having 10 nos outgoing feeders, two numbers $11 \mathrm{kv}$ bus incomes from the transformer and a bus section. Figure 2 ring1 of $6.6 \mathrm{KV}$ network. At one end of the ring, $6.6 \mathrm{KV}$ is feeding from Bus A of Panel no 106. Another end of the ring, 6.6 KV is feeding from Bus B of Panel no 105. Ring off has been made in the substation SS3 for the system stability. Substation SS1 having 1 x 1000 KVA transformer. Substation SS2 having 2 x 1000 KVA transformer. Substation SS3 having 2 x 1000 KVA transformer. Substation SS4 having 1 x 1000 KVA transformer. Substation SS5 having 1 x 1000 KVA transformer. 


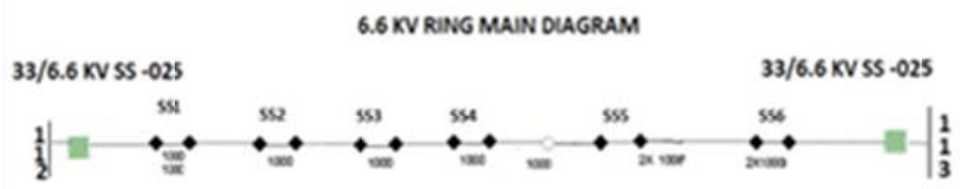

Figure 2. Typical Arrangement of a Ring1 Main Diagram of 6.6 KV Network

\subsection{Replacement of Distribution Transformer Model}

Apply outage for the required DT to be replaced. Avail the required DT outage. Reconfirm that DTs upstream/downstream circuit breakers are tripped, kept in test position/locked. Disconnect the HV/LV power cables, earthing's, etc., and make ready for recovery. Arrange to recover the DT.Parallel civil modification work to be carried out to suit for the new DT. Identification of equipment in the store, collect the equipment, transport to site and safely positioned on a foundation. Install the new DT having a dual ratio (This may be reconfirmed in the DT name plate). Also confirm the DTs vector group is as same as the previous one.Carry out the new DTs earthing. Assembly of major accessories of transformer such as radiators, conservator tank, cable box as per the supplied instructions. Fix all the accessories like HV/LV bushings, interconnecting pipes, conservator tank, radiators etc., as per the supplied manual. Fill up the new DT oil to the required level as mentioned in the O\&M manual. Check the ratio links are fixed in $11 \mathrm{KV}$. If not, change the links as per the drawings found on the name plate. Carry out DT oil drying out process as recommended by the supplier. After the DT oil temperature has come down to normal temperature, take the oil samples from the main tank, OLTC and conduct oil test (the BDV should be more than 60KV). Conduct the required DT tests like ratio test, winding resistance tests, etc., to ensure that the DT is set into the required ratio. Reconnect the old $\mathrm{HV} / \mathrm{LV}$ power cables after conducting Megger testing. If the cable length is insufficient, change the power cable with new cables. Recheck the control/protection wirings. If not, correct it as per the approved drawings. Check oil leakages from radiators, valves, etc., If oil leakages are found, attend immediately. Confirm all the status of the DT valves as per the name plate details. Carry out OLTC operations from local and as well as from remote. Carry out DT protection checks like oil temperature alarm, winding temperature alarm, Bucholtz alarm, MOG alarm, and its trip operations. Also confirm fan start/stop operations. Confirm that all the protection relays are set correctly and tested properly. Conduct functional checks like CB operations, relay operations, etc. Confirm that alarm circuits are operating each and every time. Reset all the relays/alarms. Return the work permit for DT energization.

\subsection{Procedure to Replace 6.6 KV / 0.4 KV Pocket Substation with 11 KV / 0.4 KV Substation}

Figure 3 shows a pocket substation [15] comprising a transformer, ring main unit and LVDB.SF6 Ring Main Unit (RMU) is utilized instead oil type. Easy for transportation. Compact and less weight. Easy to repair and maintenance. Limited space is required. For easy removal and replacement without major changes.

Load sparing is possible from a common point of source. For temporary supply, pocket substation is very convenient. Foundation required is very simple. Figure 4 shows a pocket substation with oil RMU.

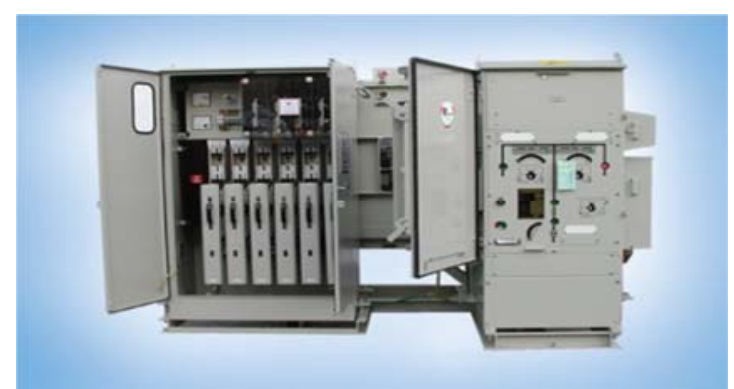

Figure 3. Typical Arrangement of 11-6.6/0.4 KV Pocket Substation with SF6 RMU

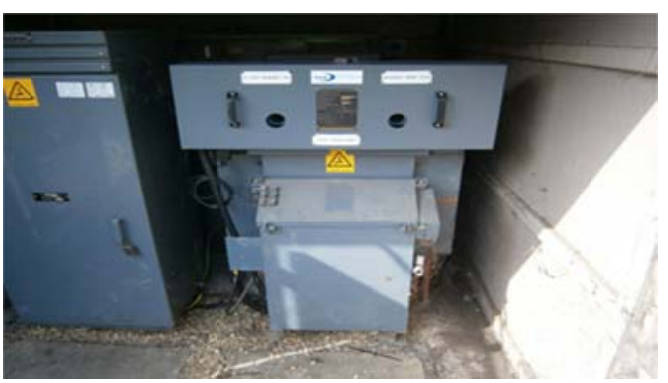

Figure 4. Typical Arrangement of 116.6/0.4 KV Pocket Substation with OIL RMU

Replacement of Pocket Substation (Transformer + LVDB + Ring Main Unit). All safety precautions to be taken before and during the work as per safety manual. Carry out a site visit in advance by the

Environment Fridently Voltage Upgradation Model for Distribution Power Systems (K. Nithiyananthan) 
concerned site engineer in Substation section. Compare the equipment details of the existing equipment and new equipment with the details mentioned in the job order. Get clarification from the planning section for any discrepancy. Obtain counter work permit and key(s) from the commissioning engineer. Note down the meter details of the existing pocket substation. If a temporary pocket is not required, follow the following steps. Remove the pocket substation after disconnecting earth leads and cables, after the phase markings are noted. Place the new pocket substation in place and re-connect the earthling leads and cables following the phase markings. Note down the meter details of the new pocket substation.

\subsection{Procedure for Replacement of Ring Main Unit}

Ring main unit (RMU) replacement is only required wherever its having the metering unit with voltage transformer as single ratio is to be replaced with dual ratio voltage transformer. All safety precautions to be taken before and during the work as per safety manual. Rigger Group to transport RMU as per Procedure. Check the site in advance and take necessary action so that shutdown can be availed for smooth execution of the job. Co-ordinate with the Commissioning and Planning engineer for outage as per commissioning program. Obtain necessary counter work permit from the concerned Substation Commissioning Engineer. Check ring cables are grounded at the respective ends and switches locked as shown in Figure 5.

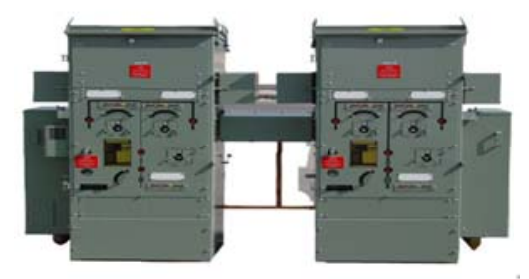

Figure 5. Typical Arrangement of SF6 Ring Main Unit

Commence disconnecting all the cables, marking the cores carefully, under the supervision of the commissioning engineer. Disconnect earthing lead. Dismantle the unit and remove out-off position. Install new Ring Main Unit. Connect earthing to Ring Main Unit. Reconnect cables as per the marking done while disconnecting, under the supervision of the commissioning engineer. Carry out all relevant checks/tests \& fill up check list, before giving clearance. Sign and return counter work permit to substation commissioning engineer. If the existing RMU contained HV Metering equipment, then the details of metering equipment to be furnished.

\subsection{Step by Step Procedure for Up Gradation of Voltage in the Network}

1) Avail the outage of DT 1 of the primary substation and bus bar 1 will be fed from the DT2 with bus section in closed condition.

2) Put the secondary voltage of DT1 from $6.6 \mathrm{KV}$ to $11 \mathrm{KV}$ ratio.

3) Energize the DT1 transformer only and check the stability.

4) Avail $11 \mathrm{KV}$ bus bar 1 outage after closing the ring off position of the entire rings.

5) Normalize the bus bar 1 which is fed from DT1.At present BB1 is $11 \mathrm{KV}$ voltage and BB2 is $6.6 \mathrm{KV}$ voltages which is serving the entire load.

6) The outage of the first secondary substation of ring one will be carried out. Connect the transformer into $11 \mathrm{KV}$ which is connected to the bus bar 1 and next secondary substation outage will take and connect to the $11 \mathrm{KV}$ and the same will repeat until all the secondary substation are connected to $11 \mathrm{KV}$ which is fed from the DT1.

7) The same process will be followed for the entire rings.

8) Now BB 1 is serving the entire load which is $11 \mathrm{KV}$ feeding from DT1.

9) Now avail the outage for DT 2 and bus bar 2 which is having $6.6 \mathrm{KV}$ supply source.

10) Change the voltage ratio from $6.6 \mathrm{KV}$ to $11 \mathrm{KV}$ of DT 2.

11) Energize the DT2 and check the stability.

12) Energize the $B B 2$ from $D T 2$. Parallel the $B B 1$ and $B B 2$ through the BS, check the stability and switches off the BS and connect the first ring to the BB2 and run off to make as earlier and the same method to adopt for the entire ring. 
13) Now the entire system is changed from $6.6 \mathrm{KV}$ to $11 \mathrm{KV}$ network.

\subsection{Equipment Analysis Model}

For implementing up gradation model equipment analysis has been carried out. The check has been made and found the Transformer of DT1 and voltage transformer is single ratio. The Distribution Transformers DT1 of 33/6.6 KV, vector group of Dyn11, capacity of $10 \mathrm{MVA}$, and the type of cooling ONAN/ONAF. And also it has been checked and found the transformer DT2 and voltage transformer is single ratio. The Distribution Transformers DT2 of 33/6.6 KV, vector group of Dyn11, capacity of 10 MVA, type of cooling ONAN/ONAF. Hence, these are to be replaced with a dual ratio of 3.3/11-6.6 KV with all parameters unchanged. The equipment analysis is to be carried out before the actual conversion and replacement of the equipments, during the analysis it has been confirmed the suitability of the substation for upgrading into $11 \mathrm{KV}$ for this purpose the following are checked in the substation. Voltage ratio of the equipment. Healthiness of the voltage. Space and access availability of the substation. Ampere capacity of the cable. Similar way Analysis for SS1 to SS5 has been carried out.Checked and found the transformer in the SS1 of the ring1 and voltage is single ratio. The Distribution Transformers in the SS1 of ring 6.6/0.4 KV, vector group of Dyn11, capacity of $1000 \mathrm{KVA}$, and the type of cooling ONAN. This transformer is to be replaced with a dual ratio of 11-6.6/0.4 KV with all parameters unchanged. During the analysis it has been confirmed the suitability of the substation for upgrading into $11 \mathrm{KV}$ for this purpose the following are checked in the substation.

\section{ESTIMATION OF TIME REQUIREMENT ANALYSIS}

Estimating the time for planning the work properly to obtain the optimum timing so that the cost of the work can be controlled. For limiting the supply interruption for the consumer time value is required.

\subsection{Time Required for Primary Substation up Gradation}

Disconnection of HV, LV and accessories, cables of the existing Distribution Transformers DT of 33/6.6 KV. Recovery of the existing the Distribution Transformers DT of 33/6.6 KV. Recovery of existing $\mathrm{HV}$ and LV cables if not suitable for the new dual ratio. Distribution Transformers DT of 33/11-6.6 KV. Civil modification to be carried out to suit for the new dual ratio Distribution Transformers DT of 33/11-6.6 KV. New dual ratio Distribution Transformers DT of 33/11-6.6 KV shifts, positioning, installation and accessories fixing. Laying of HV, LV cables and earthing of the new dual ratio Distribution Transformers DT of 33/11-6.6 KV. Connections of HV and LV cables of new dual ratio Distribution Transformers DT of 33/11-6.6 KV. HV bushing fixing and oil top up in the new dual ratio Distribution Transformers DT of 33/11-6.6 KV. Oil dries out in the new dual ratio Distribution Transformers DT of 33/11-6.6 KV. Transformer testing, relay testing \& functional checks of the new dual ratio Distribution Transformers DT of 33/11-6.6 KV. Inspection and commissioning of the new dual ratio Distribution Transformers DT of 33/116.6 KV. For the above activities minimum 10 days are required for the replacement of exiting single ratio transformer with dual ratio transformer.

\subsection{Time Analysis Model for Secondary Substation}

Disconnection and recovery of 1500, 1000, $500 \mathrm{KVA}$ transformers and re-installation of new transformer of any capacity, laying of HV \& LV cables, termination of cables on transformer and LVDB earthing and clear permit for energisation -6 hours from time of collecting counter permit. Disconnection and recovery of 1000 or 500 KVA Pocket substation and re-installation of Pocket substation of any capacity, laying of cables, termination of cables \& earthing and clear counter work permit for energisation - 6 hours from time of collecting counter permit.Disconnection, dismantling and recovery of existing RMU and installation and re-installation of new RMU laying of new/existing cables with re termination of cables with existing or new termination kit, etc. and clear counter permit for energisation -9 hours from time of collecting counter permit. Disconnection and recovery of LVDB and re-installation of new LVDB, laying and determination of single core cables \& LV feeders, etc. and clear counter work permit for energisation -7 hours from time of collecting counter work permit. Disconnection and recovery of 1500, 1000, 500 KVA transformers with RMU and re-installation of new transformer of any capacity and RMU, laying of HV \& LV cables, termination of cables on transformer and RMU and clear permit for energisation -10 hours from time of collecting counter permit. Disconnection and recovery of 1500, 1000, $500 \mathrm{KVA}$ transformers with RMU and LVDB. Re-installation of new transformer of any capacity, RMU and LVDB, laying of HV \& LV cables, termination of cables on transformer, RMU and LVDB. Clear permit for energisation -11 hours from time of collecting counter permit. Disconnection and recovery of 1500, 1000, $500 \mathrm{KVA}$ transformers and LVDB. Re-installation of new transformer of any capacity and LVDB, laying of HV \& LV cables, 
termination of cables on the transformer, and LVDB. Clear permit for energisation -09 hours from time of collecting counter permit.

\subsection{Time Required for the Actual Conversion of the Network}

Minimum two hours are required for the primary distribution transformer for changing the taps links from the $6.6 \mathrm{KV}$ ratio to $11 \mathrm{KV}$ and commissioning. Minimum 30 minutes are required for the secondary distribution cast resin transformer for changing the taps links from the $6.6 \mathrm{KV}$ ratio to $11 \mathrm{KV}$ and commissioning. Minimum 15 minutes are required for the secondary distribution oil transformer for changing the taps links from the $6.6 \mathrm{KV}$ ratio to $11 \mathrm{KV}$ and commissioning.For carrying out replacement work, various approvals like internal and external are required. This is in compliance with the existing rules and regulation and practices of the authority. Before implementing the model cost analysis has been carried out.

\subsection{Minimizing the Supply Interruption}

Mininimum supply interruption has been aimed to implement the proposed work. At the substation, transformer feeding power to the consumer, when it has been replaced this transformer for the system voltage conversion purpose, the supply is interrupted to the consumer. To minimize the interruption and the following methods are adopted for the same.

\subsubsection{Primary Substation}

During the transformer replacement in the primary substation [13] where possible considering the site condition and system requirement, the generator supply is provided to the consumer when the auxiliary transformer is out of service during the DTs replacement work. For connecting the generator approximately 30 minute power interruption is availed. Similarly, after the replacement work disconnecting the generator and connecting the transformer also required 30 minutes.

\subsubsection{Secondary Substation}

During the transformer replacement in the secondary substation [13] where possible considering the site condition and system requirement, the generator supply is provided to the consumer when the transformer is out of service during the replacement work. For connecting the generator approximately 30 minute power interruption is availed. Similarly, after the replacement work disconnecting the generator and connecting the transformer also required 30 minutes. Hence, instead the interrupted the power 6 to 8 hrs. During the replacement of the transformer, interrupt only for one hour. During the pocket substation replacement for the system conversion purpose, since LV board is replaced along with transformer and switchgear, where the generator connection is not possible. Hence, to minimize the power interruption, install the temporary pocket substation, which will feed the consumer during the replacement work. During the replacement of the pocket substation, generator along with temporary LVDB also is used to minimize the power interruption. By allocating the work to the work groups properly and well planned, then the replacement job can be speeded up, thereby power interruption is also reduced. Minimize power supply interruption to customers by alternate feeding arrangement / usage of mobile generators during the work execution. Usage of modern test equipment for faster clearance of the circuit, such as transformer turns ratio testing equipment and digital insulation testers. By using these equipment's the testing time is reduced to $25 \%$ of the time taken by the conventional methods. During the work, through the usage of modern instruments for testing the equipment, the total duration of the shutdowns was reduced. Again through an innovative way of work method, using temporary pocket substations and generators, the power interruptions to the consumers were minimized.

\section{REAL TIME CURRENT LOSS CALCULATION MODEL}

The current loss calculation model has been implemented and the current loss of all the ring mains of the substation has been calculated. The operating voltage of $6.6 \mathrm{KV}$ and $11 \mathrm{KV}$. It is found that due upgradataion of the voltage for all rings, current loss reduced by more than $50 \%$. A sample calculation model for ring 1 of the secondary substation has been explained with the operating voltage of $6.6 \mathrm{KV}$ and $11 \mathrm{KV}$.

\subsection{Current Loss Calculation of 6.6KV Circuit of the Secondary Substation Ring-1}

The Circuit is feeding from the Switchgear Panel number 106 of the primary substation to SS1 of the Secondary substation. The distance between the Primary substations to the SS1 is $3.0 \mathrm{KM}$ as shown in Figure 6. 


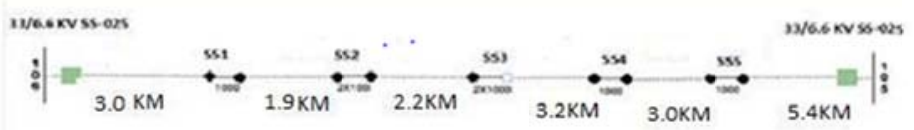

Figure 6. Typical Arrangement of a Ring1 Main Diagram of 6.6 KV Network

Then loss Calculation will be as follows.

The Resistance of HV cable is recommended by the manufacture are as 300 Sqmm HV copper cable $=0.0601$ $\Omega / \mathrm{KM}$

240Sqmm HV copper cable $=0.0754 \Omega / \mathrm{KM}$

240sqmm HV Al cable $=0.1250 \Omega / \mathrm{KM}$

The Cable resistance [17] between switch gear panel Number 106, i.e. primary substation to the SS1 is. $\mathrm{R} 1=0.0601 * 3.0=0.1803 \Omega$

$\mathrm{R} 1=0.1803 \Omega$

Calculating the current in the circuit as. $\mathrm{I} 1=\mathrm{P} / \mathrm{V}$

$\mathrm{P}=$ Power considered as $80 \%$ at full load and $40 \%$ at off load, then average of $60 \%$ loading is taken into consideration for the power calculation

$\mathrm{P}=5000 \mathrm{KVA}$ is the load as per the circuit $\mathrm{P}=3000 \mathrm{KVA}$ is the $60 \%$ load of the circuit $\mathrm{I} 1=\mathrm{P} / \mathrm{V}$

$\mathrm{I} 1=3000 / 6.6 * \sqrt{3}$

$\mathrm{I} 1=262.43 \mathrm{~A}$

Loss $=I 12 \mathrm{R} 1=(262.43) 2 * 0.1803 \Omega=12417.17$ Watts Loss L1=12.41 KW

Similarly for calculating the current loss in the circuit between SS1 and SS2 are as follows. The distance between the circuit SS1 and SS2 is $1.9 \mathrm{KM}$ and the cable in the network is $240 \mathrm{sq} \mathrm{mm}$ icopper conductor.

Then $\mathrm{R} 2=0.0754 * 1.9 \mathrm{R} 2=0.1463 \Omega$

Load in the circuit is $4000 \mathrm{KVA}$ Then $60 \%$ of the load is $2400 \mathrm{KVA}$

$$
\begin{aligned}
& \mathrm{I} 2=\mathrm{P} / \mathrm{V} \\
& \mathrm{I} 2=2400 / \sqrt{3} * 6.6 \\
& \mathrm{I} 2=209.94 \mathrm{~A} \\
& \text { Loss }=\mathrm{I} 22 \mathrm{R} 2 \\
& \text { Loss }=(209.94) 2(0.1463) \\
& \text { Loss }=6314.15 \mathrm{Watts} \\
& \text { Loss L2=31 KW }
\end{aligned}
$$

Similarly than it can find out the loss in the circuit between the SS2 and SS3 as follows. The distance between the circuit SS2 and SS3 is $2.2 \mathrm{KM}$ and the cable the circuit is a 240 sqmm aluminum conductor.

$\mathrm{R} 3=0.1250 * 2.2$

$\mathrm{R} 3=0.275 \Omega$ Load in the circuit is $2000 \mathrm{KVA}$

Then it has been considered $60 \%$ of the load is $1200 \mathrm{KVA}$ Then $\mathrm{I} 3=\mathrm{P} / \mathrm{V}$

$\mathrm{I} 3=1200 / \sqrt{3} * 6.6$

$\mathrm{I} 3=104.97 \mathrm{~A}$

Loss $=$ I32 R3 Loss $=3030.14$ watts Loss L3=3.3 KW

Calculated the losses up to the ring off substation, and then similarly in the same circuit feeding losses will be calculated from the switcher panel number 105 of the primary substation to SS5 and upto ring off substation. Then the current loss calculation will be as follows

$\mathrm{R} 5=0.0601 * 5.4$

$\mathrm{R} 5=0.324 \Omega$

Then calculating the current in the circuit as $\mathrm{I} 5=\mathrm{P} / \mathrm{V}$

$\mathrm{I} 5=2000 / \sqrt{3} * 6.6$

$\mathrm{I} 5=74.95 \mathrm{~A}$

Loss $=$ I52 R5

Loss $=(174.95) 2 *(0.324) \mathrm{L} 5=9917.5$ watts L5=9.9 KW

Similarly for calculating the current loss in the circuit between SS5 and SS4 are as follows the distance between the circuit SS5 and SS4 is $3.0 \mathrm{~km}$ and the cable in the network is $240 \mathrm{sq} \mathrm{mm}$ copper conductor cable.

Then

$\mathrm{R} 4=0.0754 * 3.0$ 
$\mathrm{R} 4=0.226 \Omega$

Then calculating the current in the circuit as $\mathrm{I} 4=\mathrm{P} / \mathrm{V}$

Power $\mathrm{P}$ in the circuit is $1000 \mathrm{KVA}$

It has been consider $60 \%$ of the load on the circuit is $600 \mathrm{KVa} \mathrm{I} 4=600 / \sqrt{3} * 6.6$

$\mathrm{I} 4=52.48 \mathrm{~A}$

Loss $=\mathrm{I} 42 \mathrm{R} 4$

Loss $=(52.48) 2 *(0.226) \mathrm{L} 4=622.98$ watts L4 $=0.622 \mathrm{~kW}$

The sum of the current losses in the Ring 1 circuit is $\mathrm{L} 11=(\mathrm{L} 1+\mathrm{L} 2+\mathrm{L} 3+\mathrm{L} 4+\mathrm{L} 5)$

Therefore $\mathrm{L} 11=(12.41+3.03+6.31+0.62+9.17)$

$\mathrm{L} 11=31.54 \mathrm{~kW}$

\subsection{Current Loss Calculation of 11 KV Circuit of the Secondary Substation Ring -1} follows.

The same ring 1 as shown in Figure 6 has been considered of $11 \mathrm{KV}$ for loss Calculation will be as

The Resistance of HV cable is recommended by the manufacture are as $300 \mathrm{Sqmm}$

$\mathrm{HV}$ copper cable $=0.0601 \Omega / \mathrm{KM}$.

$240 \mathrm{Sqmm}$ HV copper cable $=0.0754 \Omega / \mathrm{KM}$

240 sqmm HV Al cable $=0.1250 \Omega / \mathrm{KM}$

The Cable resistance between switch gear panel Number 106, i.e. primary substation to the SS1 is. $\mathrm{R} 1=0.0601 * 3.0=0.1803 \Omega$

$\mathrm{R} 1=0.1803 \Omega$ Calculating the current in the circuit as.

$\mathrm{I} 1=\mathrm{P} / \mathrm{V}$

$\mathrm{P}=$ Power considered as $80 \%$ at full load and $40 \%$ at off load, then average of $60 \%$ loading is taken into consideration for the power calculation

$\mathrm{P}=5000 \mathrm{KVA}$ is the load as per the circuit $\mathrm{P}=3000 \mathrm{KVA}$ is the $60 \%$ load of the circuit $\mathrm{I} 1=\mathrm{P} / \mathrm{V}$

$\mathrm{I} 1=3000 / 11 * \sqrt{3} \mathrm{I} 1=157.45 \mathrm{~A}$

Loss $=I 12 \mathrm{R} 1=(157.45) 2 * 0.1803=4469.72 \mathrm{Watts}$

Loss L1 $=4.46 \mathrm{KW}$

Similarly for calculating the current loss in the circuit between SS1 and SS2 are as follows.

The distance between the circuit SS1 and SS2 is 1.9 Meters and the cable in the network is 240 sq mm copper conductor.

Then

$\mathrm{R} 2=0.0754 * 1.9$

$\mathrm{R} 2=0.143 \Omega$

Load in the circuit is $4000 \mathrm{KVA}$ Then $60 \%$ of the load is $2400 \mathrm{KVA}$

$\mathrm{I} 2=\mathrm{P} / \mathrm{V} \mathrm{I} 2=2400 / 11 * \sqrt{3}$

$\mathrm{I} 2=125.96 \mathrm{~A}$

Loss $=I 22$ R2

Loss $=(125.96) 2(0.143)$

Loss $=2268.8$ Watts

Loss L2=2.26 KW

Similarly than it has been find out the loss in the circuit between the SS2 and SS3 as follows. The distance between the circuit SS2 and SS3 is $2.2 \mathrm{KM}$ and the cable the circuit is a 240 sqmm aluminum conductor.

$\mathrm{R} 3=0.1250 * 2.2$

$\mathrm{R} 3=0.275 \Omega$ Load in the circuit is $2000 \mathrm{KVA}$

Then considered $60 \%$ of the load is $1200 \mathrm{KVA}$ Then I3=P/V

$\mathrm{I} 3=1200 / 11 * \sqrt{3}$

$\mathrm{I} 3=62.98$ A Loss $=\mathrm{I} 32 \mathrm{R} 3$

Loss $=(62.98) 2(0.275)=1090.78$ watts

Loss L3=1.09 KW

Calculated the losses up to the ring off substation, and then similarly in the same circuit feeding losses will be calculated from the switcher panel number 105 of the primary substation to SS5 and upto ring off substation. Then the current loss calculation will be as follows

$\mathrm{R} 5=0.0601 * 5.4$

R5 $=0.324 \Omega$

Then calculating the current in the circuit as $\mathrm{I} 5=\mathrm{P} / \mathrm{V}$

I5 $=2000 / 11 * \sqrt{3}$ I5=104. $97 \mathrm{~A}$

IJECE Vol. 6, No. 6, December 2016 : 2516-2525 
Loss $=\mathrm{I} 52 \mathrm{R} 5$

Loss $=(104.97) 2 *(0.324) \mathrm{L} 5=3570.05$ watts L5=3. $57 \mathrm{KW}$

Similarly for calculating the current loss in the circuit between SS5 and SS4 are as follows The distance between the circuit SS5 and SS4 IS $3.0 \mathrm{~km}$ and the cable in the network is 240 sqmm copper conductor cable. Then

$\mathrm{R} 4=0.0754 * 3.0$

$\mathrm{R} 4=0.22 \Omega$

Then calculating the current in the circuit as

$\mathrm{I} 4=\mathrm{P} / \mathrm{V}$

Power in the circuit is $1000 \mathrm{KVA}$

It has been considered $60 \%$ in the circuit is $600 \mathrm{KVa} \mathrm{I} 4=600 / 11 * \sqrt{3}$

I4=31. 49 A Loss $=I 42$ R4

Loss $=(31.49) 2 *(0.22) \mathrm{L} 4=218.15$ watts L4 $=0.218 \mathrm{~kW}$

The sum of the current losses in the Ring 1 circuit is $\mathrm{L} 11=(\mathrm{L} 1+\mathrm{L} 2+\mathrm{L} 3+\mathrm{L} 4+\mathrm{L} 5)$

Therefore $\mathrm{L} 11=(4.46+2.26+1.09+3.57+0.21)$

$\mathrm{L} 11=11.59 \mathrm{~kW}$

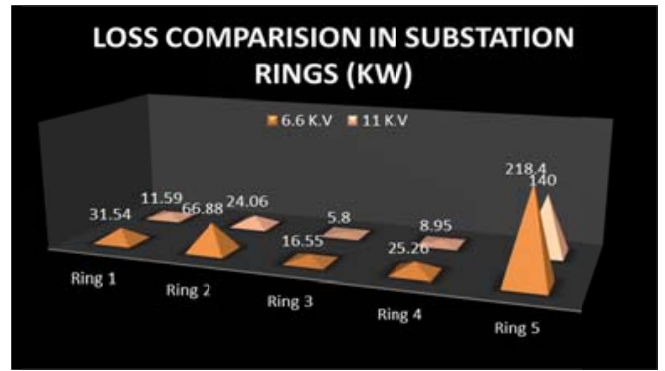

Figure 7. Current Loss Comparison in Secondary Substation Ring Mains

Figure 7 shows the comparison of sum of energy loss occurred in the secondary substation ring mains for $6.6 \mathrm{~K} . \mathrm{V}$ and $11 \mathrm{~K} . \mathrm{V}$ network. It has been found that for the same load current from ring 1 to 5 there is considerable reduction in the loss for $11 \mathrm{~K} . \mathrm{V}$ distribution network compare to $6.6 \mathrm{~K}$.V network. In this environmentally friendly model total loss occurred is $190.4 \mathrm{KW}$ compared to the conventional $6.6 \mathrm{~K}$.V operating voltage is $358.58 \mathrm{~K}$.W. It is evident that around $50 \%$ of energy can be saved by upgrading the network from $6.6 \mathrm{~K} . \mathrm{V}$ to $11 \mathrm{~K} . \mathrm{V}$. The proposed research work which results in reduction of the operational current while power consumption is constant. It has been proved that all the developing nations required to implement the low cost energy transmission model to save energy which in turn save the environment.

\section{CONCLUSION}

The proposed model improves the Network efficiency and allows higher number of connections to 11/0.4 KV substations without the need to lay additional $11 \mathrm{KV}$ cables. This means better and effective utilization of the existing resources, since the current network cable utilization increases. Decreasing the number of cables in the corridor and reducing the load per ring, this in turn prolongs the cable life and increases network reliability. Reduction in Energy losses of the Distribution network. Reduction in Voltage drops of the Distribution network. Reduction in Voltage Regulation of the Distribution network. Due to a reduction in the losses, the requirement of power generation reduces. Hence, the usage of fuel and emissions related to power generation reduces, which in turn, reduce the environmental impact. The overall resources and manpower requirement also reduce correspondingly. The quantity of cables required to distribute the power has become less of this work since the current decreases as the voltage increases, for the same power. This, in turn, leaves more space underground. Again, the materials required for the production of cables, becomes less. Hence, the environmental impact, by consuming the raw materials, also becomes less. The pollution caused by the production factories is reduced due to the reduced production requirement. Increase the system voltage that results in the reduction of the current passing through, which results in an increase in the number of substations that can be added to each circuit and accordingly the number of customers. Overall cost reduction and efficiency results in improvement of generating unit. Reduces utilization of new cable. The new system offers greater reliability at lower cost. The customer can also use the same cables to add new

Environment Fridently Voltage Upgradation Model for Distribution Power Systems (K. Nithiyananthan) 
loads. Hence the detailed study was conducted and resources requirement and time requirement were accessed. This work was implemented along with overcoming all the constraints. During this research work, all the permissions and approvals have been applied and the same was obtained. The up gradation model can be implemented throughout and extended for large electric power distribution systems.

\section{REFERENCES}

[1] D.L. Wall, G.L. Thompson, J.E.D. Northcote-Green, "An Optimization Model for Planning Radial Distribution Networks”, IEEE Transactions on Power Apparatus and Systems, Vol. 98, No. 3, May/June 1979, PP. 1061-1068.

[2] G.L. Thompson, D.L. Wall, "A Branch and Bound Model for Choosing Optimal Substation Locations", IEEE Transactions on Power Apparatus and Systems, Vol. 100, No. 5, May 1981, PP 2683-2688.

[3] I. Sun, D.R. Farris, P.J. Cote, "Optimal Distribution Substation and Primary Feeder Planning via the Fixed Charge Network Formulation", IEEE Transactions on Power Apparatus and systems, Vol. 101, No. 3, March 1982, PP. 602-609.

[4] T.H. Fawzi, K.F. Ali, S. M. El-Sobki, “A New Planning Model for Distribution Systems”, IEEE Transactions on Power Apparatus and Systems, Vol. 102, No. 9, September 1983, PP. 3010-3017.

[5] M.A. El-Kady, "Computer-Aided Planning of Distribution Substation and Primary Feeders", IEEE Transactions on Power Apparatus and Systems, Vol. 103, No. 6, June 1984, PP. 1183-1189

[6] Boardman, C. Meckiff, "A Branch and Bound Formulation to An Electricity Distribution Planning Problem", IEEE Transactions on Power Apparatus and Systems, Vol. 104, No. 8, August 1985, PP. 2112-2118.

[7] H.K. Youssef, R. Hackam, M.A. Abu-El-Maghd, "Novel Optimization Model for Long Range Distribution Planning", IEEE Transactions on Power Apparatus and Systems, Vol. 104, No. 11, ember 1985, PP. 3195-3202.

[8] T. Gönen, I.J. Ramirez-Rosado, "Optimal Multi-Stage Planning of Power Distribution Systems", IEEE Transactions on Power Delivery, Vol. 2, No. 2, April 1987, PP. 512-519.

[9] A.C. Marshall, T.B. Boffey, J.R. Green, "Optimal Design of Electricity Distribution Networks", IEE Proceedings Generation, Transmission and Distribution, Vol. 138, No. 1, January 1991, PP. 69-77.

[10] E. Miguez, J. Cidras, E. Diaz-Dorado, “An Improved Branch-Exchange Algorithm for Large-Scale Distribution Network Planning”, IEEE Transactions on Power Systems, Vol. 17, No. 4, November 2002, PP. 931-936.

[11] V. Miranda, J.V. Ranito, L.M. Proenca, "Genetic Algorithms in Optimal Multistage Distribution Network Planning”, IEEE Transactions on Power Systems, Vol. 9, No. 4, November 1994, PP. 1927-1933.

[12] S.K. Goswami, "Distribution System Planning Using Branch Exchange Technique", IEEE Transactions on Power Systems, Vol. 12, No. 2, May 1997, PP. 718-723.

[13] Don Jacob, Nithiyananthan.K, 'Effective Methods for Power System Grounding', WSEAS Transactions on Business and Economics, USA. 30-642,2008.

[14] Don Jacob, Nithiyananthan.K, 'Smart and micro grid model for renewable energy based power system', International Journal of Engineering Modelling, Croatia, EUROPE, 2009, Vol. 22, No 1-4, pp. 89-94.

[15] Elavenil. V, Nithiyananthan. K, 'CYMGRD Based Effective Earthling Design Model for Substation', International Journal for Computer Applications in Engineering Sciences Asia, 2011, Vol. I, No 3, pp. 341-346

[16] Western power, "Submission to the Econ Regulation Authority for Major Augmentation Proposal" Australia, 2010.

[17] Pratap Nair and Nithiyananthan. K 'Effective cable sizing model for buildings and Industries', International Journal of Electrical and Computer Engineering, Asia. 2016, Vol 5, 1, pp 1-8. 